\title{
De que vida trata a Biopolítica? Considerações sobre a inversão foucaultiana da máxima aristotélica
}

\author{
With what life does Biopolitics deal? Considerations on the \\ Foucaultian inversion of the Aristotelian maxim
}

\section{Marcos Nalli*}

Universidade Estadual de Londrina (UEL), Londrina, PR, Brasil

\section{Resumo}

Neste artigo pretendo refletir sobre o sentido da afirmação foucaultiana à máxima de Aristóteles de que o homem era um animal vivo capaz de existência política, enquanto no homem moderno é a sua vida que está em questão política. O que tentarei mostrar é que não se trata de uma inversão entre os termos da vida e da política, mas uma transformação radical da relação pela introdução de um elemento novo, a vida num enquadramento biológico.

Palavras-chave: Foucault. Aristóteles. Vida. Biopolítica.

\section{Abstract}

In this article, I intend to reflect on the meaning of Foucault's assertion to Aristotle's maxim that man was a living animal capable of political existence while in modern man it is his life

*MN: Doutor em Filosofia, e-mail: marcosnalli@yahoo.com 
that is in a political question. What I will try to show is that this is not a reversal between the terms of life and politics, but a radical transformation of the relationship by the introduction of a new element, life in a biological framework.

Keywords: Foucault. Aristotle. Life. Biopolitics.

É notória a afirmação de Foucault sobre a concepção aristotélica entre homem, vida e política, e a afirmação que ele fez para, a partir daquela concepção, caracterizar a vida como objeto-mor da biopolítica, em La volonté de savoir (1976): “O homem, durante milênios, permaneceu o que era para Aristóteles: um animal vivo e, além disso, capaz de existência política; o homem moderno é um animal, em cuja política, sua vida de ser vivo está em questão" (FOUCAULT, 1976, p. 188; 1988, p. 134). Esta declaração vem sendo constantemente ensejada, mais em virtude de sua força retórica do que em razão de sua precisão conceitual: é mais a tese de que a vida se tornou entre nós, os modernos, questão política que motiva sua ampla utilização como espécie de lema para se pensar as mais diversas e variadas nuances das estratégias e governos biopolíticos, que pelo menos desde os fins do século XIX foram engendrados e politicamente viabilizados.

Mas outra pergunta a se fazer é se o sintagma "vida", comum a Aristóteles e toda uma tradição que se formou, principalmente no Ocidente com base nele, comporta a mesma carga conceitual que para nós, os modernos, principalmente sob a égide de uma plêiade de acontecimentos sócio-políticos, científicos e tecnológicos, que denominamos "biopolítica". Afinal, com o termo "vida" se passou a designar um conjunto bastante variado de fenômenos, tanto numa perspectiva mais biológica, quanto numa perspectiva política, passando ainda por uma forte exploração filosófica após a fenomenologia - tradição essa, aliás, a que Foucault não passou alheio, ainda que lhe soube manter um posicionamento e distância crítica (NALLI, 2006). 
Curiosamente, e isto justifica ao menos parcialmente minha alusão à força retórica daquela citação, Foucault parece negligenciar algo que sempre foi muito caro em todos os seus trabalhos quando a cita: a de que um sintagma ganha historicamente contornos conceituais variados, de tal modo que se pode constituir ao menos semanticamente um objeto todo novo de investigação e intervenção (Cf. NALLI, 2006, p. 111-127). Ou dito de outro modo: quando Foucault faz esta afirmação, parece que ele esquece momentaneamente a necessidade de considerar, numa perspectiva histórica - seja pela arqueologia, seja genealogicamente - o acontecimento que quer considerar: no caso, a própria história do conceito de vida e dos fenômenos (para não dizer objetos) a que ele designa. Sequer a referência a Aristóteles desempenha uma estratégia pura e simples de comparação, ou ainda de demarcação histórica do arco de transformação, como aquelas que se encontram no prefácio à primeira edição de Histoire de la folie (1961), no prefácio de Naissance de la clinique (1963) ou da introdução de Surveiller et punir (1975), nos quais ele arma uma situação de contraposição entre dois exemplos e se põe a investigar historicamente - ou para ser mais preciso, arqueológica ou genealogicamente - os acontecimentos que impactaram à mudança de um polo ao outro.

Afinal, com a citação, dela não decorre realmente tal investigação. Ao máximo, ela surge quase que como um corolário no livro, sendo que ele opera um "ligeiro" deslocamento em relação à temática geral do livro, já que o livro trata do que Foucault chamou de dispositivo da sexualidade - numa abordagem híbrida de análise e distanciamento crítico a toda uma tradição teórico-crítica que advoga a tese da repressão ao sexo - para só ao final se dedicar ao tema da biopolítica e do biopoder, tema que, como se sabe, ele já havia trabalhado no começo daquele ano de 1976 no curso Il faut défendre la société. Ao que parece, com aquela referência, o que Foucault pretendia era considerar a transformação, numa quase inversão, da relação entre política e vida da época de Aristóteles até nossa época moderna.

Desse modo, o que se pode investigar é se a partir da trama dessa inversão, os próprios termos definidores do que se pode entender tanto por vida quanto por política também mudaram, e talvez até de modo 
radical, exigindo novos e diferentes modos de se pensar, dizer e agir politicamente. $\mathrm{O}$ que, se confirmado, implica em admitir que não se trata criticamente de buscar uma espécie de retorno romântico e idílico a um passado memorial idealizado, e sim de buscar de modo pungente por um modo de prática - discursiva e política - condizente e apropriado ao tempo presente.

A inversão, então identificada por Foucault e que, segundo ele, se dá já no alvorecer da Modernidade, parece apontar para uma condição fundamental à emergência histórica das estratégias biopolíticas, geralmente implementadas a partir do início do século XIX, qual seja: é possível admitir alguma estrutura comum entre as ciências e as práticas políticas e governamentais de modo a consistir num todo único, para além da mera coincidência fortuita. Ou seja, sua inversão não se dá meramente por razões e motivações políticas, de estratégias governamentais; mas também por força de inflexões então introduzidas pelas ciências. Por isso, há que se investigar sobre a natureza epistêmica da noção de vida já na biopolítica. Ou melhor, da "coincidência estrutural" entre o acontecimento histórico da biologia e da biopolítica ${ }^{1}$.

Neste sentido, para tentar compreender o sentido e as implicações daquela afirmação e de sua aparentemente insuspeita inversão, pode se fazer interessante resgatar como Foucault considerou, ao menos em termos arqueológicos, a transformação e constituição epistêmica da noção de vida, e depois pensar se tal abordagem continua a reverberar genealogicamente em sua interpretação da biopolítica. Em outras palavras, há que se reconstruir - ainda que de modo bastante esquemático - alguns elementos capitais à história da conexão entre biologia e política. É preciso tentar encontrar seus pontos de conexão estrutural. Foucault fez isto, ainda que parcialmente, em duas ocasiões, exatamente no mesmo ano de 1976: em seu curso Il faut défendre la société e no primeiro volume de sua Histoire de la sexualité: la volonté de savoir. No curso, o enfoque genealógico - e, portanto, numa perspectiva histórica - recaiu sobre a questão da história do racismo, e, no livro,

1 Ademais, é possível ainda admitir outro dado capital a esta hipótese: a natureza dos objetos epistêmicos pode ser considerada em um sentido técnico e, por isto, tal acepção afeta de modo significativo a biopolítica. 
o acento foi ao tema da sexualidade. Talvez o ponto possa ser melhor explicitado se resgatarmos o modo como Foucault considera em Les mots et les choses a questão da vida, do surgimento da história natural em direção à biologia, como pano de fundo para entender o curso e o livro de 1976. Assim, então, que se volte primeiro a esse livro de 1966.

Não me interessa aqui considerar a leitura arqueológica da noção de episteme, sobre seus alcances e limites, ainda que se possa fazer necessária alguma consideração pelo menos como "pano de fundo". Como é sabido, Foucault estava interessado em rastrear arqueologicamente a formação das ciências humanas e das filosofias do sujeito na Modernidade. Para tanto, compreendia como necessário mostrar os elementos de passagem e transformação dos sistemas de pensamento da Idade Clássica para a Idade Moderna. Ou no dizer mesmo de Foucault:

[...] em toda cultura, entre o uso do que se poderia chamar os códigos ordenadores e a as reflexões sobre a ordem, há a experiência nua da ordem e de seus modos de ser. [...] Trata-se de mostrar o que ela veio a se tornar, desde o século XVI, no meio de uma cultura como a nossa: de que maneira, refazendo, como que contra a corrente, o percurso da linguagem tal como foi falada, dos seres naturais, tais como foram percebidos e reunidos, das trocas, tais como foram praticadas, nossa cultura manifestou que havia ordem e que às modalidades dessa ordem deviam as permutas suas leia, os seres vivos sua regularidade, as palavras seu encadeamento e seu valor representativo; que modalidades de ordem foram reconhecidas, colocadas, vinculadas ao espaço e ao tempo, para formar o suporte positivo de conhecimentos tais que vão dar na gramática e na filologia, na história natural e na biologia, no estudo das riquezas e na economia política (FOUCAULT, 1992, p. 11).

A mim, interessa aqui considerar apenas alguns traços dessa experiência nua da ordem e de seus modos de ser, que permitam identificar as condições de possibilidade da biologia, da vida como sua positividade por excelência e condição à sua configuração epistêmica. E disso se perguntar se não está já aí também a possibilidade de sua 
configuração, não apenas a um conhecimento, mas também a práticas e estratégias eminentemente políticas. Como Foucault descreve arqueologicamente essa experiência nua da ordem que culminou, em nossa Modernidade, na biologia?

Sua primeira consideração é uma crítica, ou ao menos um esmaecimento dos limites de demarcação entre mecanicismo, sustentado pela figura de Descartes, e o vitalismo. Foucault buscou encontrar o que, para além das aparências, une a imagem do organismo àquela da máquina. E isto por uma razão simples ao mesmo tempo que controversa - de outro tipo, já que Foucault não participa do debate, e sim se coloca fora, buscando enxergar outros elementos - de um ponto de vista histórico; qual seja a de que, contrário ao que querem os historiadores da biologia, não há como fazer uma história da biologia até o século XVIII pelo simples fato de que a biologia não existia, e de que não se pode praticar um presenteísmo historicista pelo qual se busca reconhecer num passado nem tão distante elementos históricos que nos são familiares: "se a biologia era desconhecida, o era por uma razão bem simples: é que a própria vida não existia. Existiam apenas seres vivos e que apareciam através de um crivo do saber constituído pela história natural" (FOUCAULT, 1992, p. 141, grifo do autor).

A biologia não existia até o século XVIII. E não existia porque seu objeto não existia: não existia a vida. Existiam apenas seres vivos (FOUCAULT, 1992, p. 175). Segundo Foucault, a história natural também pode ser historicamente datada, ainda que isto não seja exatamente o mais importante nesse ponto de sua argumentação. A novidade então introduzida a uma história que - pelo menos a partir de 1657, com a publicação de Historia naturalis de quadripedidus, de Jan Jonston em Amsterdã; portanto mais ou menos contemporânea das Meditações de Descartes, de 1641 - se dá pelo esforço de dizer tudo sobre o que vê, mas acompanhado por um esforço de ver menos, de se ter uma moderação no olhar dos seres vivos e só se poder falar do que se vê em sentido estrito, e que só se pode nomear o que de fato for da ordem da representação. Não se busca mais o espetacular e o monstruoso ainda que não deixem por isso de existirem - , como no Renascimento; busca-se apenas o que pode ser observado, despido de todas as suas 
valorações e qualia. Há que apenas observar e descrever o que se observa. A nomeação das coisas advém dessa conexão no nível da mera e residual observação a partir de "condições sistematicamente negativas" (FOUCAULT, 1992, p. 146) de tudo que pode extrapolar os limites de sua experiência. É no quadro deste entrecruzamento com as palavras que a vida se coloca, como uma marca que pode ser dita ou não, que corresponde a algum signo ou não: “O naturalista é o homem do visível estruturado e da denominação característica. Não da vida" (FOUCAULT, 1992, p. 176).

É justamente a partir do último quarto do século XVIII e o primeiro do século XIX que mudanças drásticas ocorrem na ordem dos saberes - vale lembrar que Les mots et les choses, como uma arqueologia das ciências humanas, se estrutura em torno de uma análise da constituição de três grandes temas ou objetos, a saber o trabalho, a linguagem e a vida - desligada do primado da representação estrutural e estruturada, porque é fixa e atrelada a um sistema de comparações, de articulação e designação para outro, voltada "ao Tempo, ao seu fluxo, a seus retornos, porque presa ao modo de ser da História" (FOUCAULT, 1992, p. 134). Foucault compreende esta transformação, num período aproximado de 50 anos, como tendo dois grandes momentos, o primeiro compreendendo aproximadamente aos anos de 1795-1800, em que ainda preso ao tema da representação, articula como um problema a ordem das palavras e a ordem dos seres. Os princípios gerais da taxinomia ainda continuam válidos, ainda se descreve estritamente o que se vê. No entanto, se introduz um elemento capital de descontinuidade, um novo princípio: a classificação descritiva dos seres se dá a partir de então pelo princípio da organização², que não se justapõe

2 François Jacob, em A lógica da vida (cujo título original, mais corretamente é La logique du vivant), argumenta numa sutileza que ora lembra Foucault, ora se distancia dele, da entrada em cena, em fins do século XVIII, do princípio da organização: "No fim do século [XVIII] modificam-se [...] as relações entre 0 exterior de um ser e 0 interior, entre a superfície e a profundidade, entre órgãos e funções. 0 que se torna acessível à análise pela comparação dos organismos é um sistema de relações que se articulam na espessura do ser vivo para o fazer funcionar. Por detrás do visível das formas projecta-se uma arquitetura secreta imposta pela necessidade de viver. Esta estrutura de segunda ordem é a organização, que reúne numa mesma coerência 0 que se vê e 0 que se oculta. [...] É a organização que dá aos seres vivos a lei interna que rege a própria possibilidade da sua existência" (JACOB, 1985, p. 91). Vale observar que enquanto Jacob vê nisso a "emancipação" da biologia dos demais saberes da natureza, da própria história natural, Foucault identifica uma espécie de mutação do próprio solo

Rev. Filos., Aurora, Curitiba, v. 31, n. 52, p. 94-117, jan./abr. 2019 
à nomenclatura; antes se lhe coloca perpendicularmente, e é no seu entrecruzamento que os caracteres passam, então, a ser nomeados. Dessa introdução, ocorre a quebra de paralelismo entre classificação e nomenclatura e sua consequência maior implica na substituição da velha articulação dos quatro reinos - o mineral, o vegetal, o animal e o humano - , e mais até sua impossibilidade, impondo outra divisão, aquela entre o orgânico e o inorgânico. Vicq d'Azyr e Lamarck são para Foucault exemplares aqui; o primeiro define os dois reinos a partir do princípio da vida como usufruto, e o segundo define a vida e a morte como "forças poderosas, muito distintas e sempre em oposição entre si" (LAMARCK, apud FOUCAULT, 1992, p. 247). É a partir desse momento que a biologia se torna possível, e a vida e a morte são como que seu efeito e ao mesmo tempo condição fundamental, principalmente a vida ${ }^{3}$ como noção "indispensável à ordenação dos seres naturais" (FOUCAULT, 1992, p. 243).

Se com Lamarck se abre a possibilidade da constituição histórica da biologia, é com Cuvier que a sua emergência ganha a primeira versão mais acabada (FOUCAULT, 1992, p. 291), ao dissociar por completo a relação clássica entre taxinomia e a subordinação dos caracteres dos seres vivos. Já vimos antes que papel exerceu a introdução do princípio da organização para o surgimento da biologia. A novidade introduzida por Cuvier é que as estruturas de caracteres dos seres vivos não são mais concebidas apenas para permitir alguma classificação; os

arqueológico, fundacional, que permitiu o surgimento de saberes como a biologia. As explicações para essa distinção podem ser várias, principalmente que o escopo geral dos dois livros não são os mesmos, ou que talvez Jacob considere a questão numa perspectiva demasiado cientificista, enquanto Foucault opta por um posicionamento paradoxal, ao mesmo tempo dentro e fora dos saberes e das ciências constituídas, o que Ihe permite formular uma arqueologia às ciências humanas, ou ainda, que em 1966 está suficientemente atrelado a algumas demandas estruturalistas, como a da preeminência teórica ao âmbito do discursivo frente à prática e às coisas. Pouco importa. De fato, 0 que interessa é Jacob, à época que trabalha na redação de Logique du vivant, conhece Les mots et les choses e é, segundo Foucault (1994, p. 524), influenciado por este.

3 Ainda que Foucault já reconheça em Les mots et les choses a importância da morte, da finitude para pensar a emergência história da vida como esse duplo empírico-transcendental (cf. FOUCAULT, 1992, p. 259 e 265) pelo qual se ordena todo uma nova configuração, todo um novo saber, a biologia, a morte, só entra aqui num quadro de ordenação que impõe 0 tratamento dos seres vivos não mais na ordem espacial das classificações, e sim na ordem temporal das gêneses e dos desenvolvimentos dos seres. A questão da morte não assume para ele um papel tão acentuado como em suas análises, dez anos após, sobre biopolítica, em que implica na identificação crítica não dos limites da (bio)política, mas em sua "natureza", ou melhor em sua condição de existência, e exercício paradoxal. Para tanto cf. Nalli $(2012,2014)$. 
caracteres são a partir de então considerados mediante suas funções. Desse modo, o primeiro movimento não é mais o da determinação classificatória das identificações e sim de sua funcionalidade, da utilidade de um órgão, "de sorte que a diversidade visível das estruturas não mais emerge do fundo de um quadro de variáveis, mas do fundo de grandes unidades funcionais suscetíveis de se realizarem e de cumprir se fim de maneiras diversas" (FOUCAULT, 1992, p. 280), reintroduzindo assim, nos termos de Foucault, as "analogias de tipo aristotélico" (ibid.), sendo que as classificações e as analogias são propriedades do ser vivo à medida que fundadas na vida.

Assim, pode-se investigar como uma variação semântica de um sintagma era objeto de consideração analítica por parte de Foucault: justa e precisamente como ele trabalha a transformação do conceito de vida com base na substituição da planta para o animal como modelo e baliza de constituição semântica, por ocasião da passagem epistêmica entre história natural para a biologia, em Les mots et les choses:

Se o ser vivo é uma classe de seres, a erva, melhor que tudo, enuncia sua límpida essência; mas se o ser vivo é manifestação da vida, o animal deixa melhor perceber o que é o seu enigma. [...] Transferindo sua mais secreta essência do vegetal ao animal, a vida abandona o espaço da ordem e volta a ser selvagem (FOUCAULT, 1992, p. 293).

Davide Tarizzo (2010) interpreta tal passagem como a abertura em direção a uma ontologia, uma ontologia selvagem - não nos termos de Merleau-Ponty (1971; cf. CHAUÍ, 1983) com vistas a abarcar a apreensão pré-reflexiva das coisas e do mundo a partir da carne contra o corpo e contra o cogito - mas como uma ontologia da vida pela qual se pode dar conta de entender nossa modernidade, na qual nós não somos, nós vivemos. O que, aliás, era de certo modo a perspectiva a que Foucault chegava em Les mots et les choses, quando afirma que:

A experiência da vida apresenta-se, pois, como a lei mais geral dos seres, o aclaramento dessa força primitiva a partir da qual eles são; ela 
funcional com uma ontologia selvagem que buscasse dizer o ser e o não-ser indissociáveis de todos os seres. Mas essa ontologia desvela uma forma precária e secretamente já os mina por dentro, para os destruir. Em relação à vida, os seres não passam de figuras transitórias e o ser que eles mantêm, durante o episódio de sua existência, nada mais é que sua presunção de subsistir (FOUCAULT, 1992, p. 294).

Só que em Foucault tal argumento o leva em direção à descoberta da finitude e da morte como limite do conhecimento e dos seres, ainda que não de modo equivalente, pois ao conhecimento esse aniquilamento da vida pela própria vida apenas escancara seus limites, enquanto que "a própria vida destrói os seres" (FOUCAULT, 1992, p. 294). Em Tarizzo, todavia, há toda uma explanação inicial sobre a natureza ontológica da vida, a saber: (a) a vida como unidade sintética, (b) a vida como uma força secreta, e (c) a vida como uma vontade obscura de Si (cf. TARIZZO, 2010, p. IX-X). É com base no argumento em torno de uma vontade autônoma que Tarizzo se concentrará, naquela ocasião, com vistas a ampliar a senda aberta por Foucault, numa perspectiva ontológica com implicações epistemológicas, mais do que morais ou políticas; fazendo para isso um trabalho mais voltado à história da filosofia moderna, ainda que de modo mais heterodoxo.

Ora, aquela citação de Les mots et les choses remete exatamente ao limiar epistêmico que separa a Idade Clássica, marcada prioritariamente pela ordem e pela representação, da Idade Moderna (que de algum modo ainda é a nossa), cujo modelo de inteligibilidade, ou melhor, cujo sistema de pensamento se caracteriza pela historicidade e pelo dinamismo inerente aos fenômenos (CASTRO, 2004, p. 170). No caso em tela para pensar a vida, Foucault mostra a saída do modelo botânico para o modelo zoológico; isto é, como se supera a Idade Clássica no que tange à vida, cuja perspectiva é a da classificação taxonômica, e emerge na Modernidade um novo modo de encarar a vida, sustentado numa dinâmica de animalidade.

Mais que isso, o que se dá na Modernidade é algo como que um retrocesso diante da Idade Clássica e sua tendência a uma formalização 
ordenada ${ }^{4}$. Eis porque Foucault pôde afirmar sobre uma volta a modelos de analogia aristotélicos, assim como sustentar que com o modelo animal a vida volta a ser selvagem, isto é, desprovida de uma ordenação prévia projetada sobre os mais diversos seres. Neste sentido, portanto, quando Foucault retoricamente parece inverter a máxima aristotélica sem questionar teoricamente o conceito mesmo de vida, ele retoma, ou ao menos faz reverberar em sua análise da biopolítica o retorno à selvageria em virtude do novo modelo de inteligibilidade e pensabilidade que é o modelo animal, zoológico. Dito de outro modo, ao menos parcialmente a inversão foucaultiana da máxima aristotélica - se aceitamos o argumento agambeniano (1997) de que há uma disjunção nos gregos entre a vida pura e simples (zoon) e a possibilidade de uma forma política à vida (bíos) - se sustenta na animalização da vida, traço distintivo de nossa Modernidade. Seguindo os termos da formulação foucaultiana sobre Aristóteles, a vida é um substrato primevo que serve de base a uma competência, a uma pragmática política; mas é ao mesmo tempo um paradoxo, pois é uma condição de possibilidade à política sem necessariamente lhe fazer parte: a condição de vivente do homem é seu limite e seu limiar; a política é apenas um a mais que se colocar a sua existência de ser vivente. A partir do alvorecer da modernidade, não é mais da condição vivente como condição e limite da política que está em questão, e sim algo novo, a vida como questão ao mesmo tempo biológica (no sentido mais lato do termo) e política. Portanto, a inversão ponderada por Foucault não é apenas da ordem entre vida e política no que tange ao humano, mas da própria noção de vida - ainda que não fique claro pela "simples" leitura da máxima, expressa em Volonté de Savoir. E essa inversão é possível pela substituição da noção de vida como um caráter para uma noção de vida como princípio. O que parece não ter nada que ver com a questão aristotélica: em certa medida, a vida não existe em Aristóteles. Por isso, Foucault fala acerca do estagirita que o homem é um animal vivo - a distinção que Agamben resgata entre zoon e bíos dá conta apenas disso e não de

40 que, aliás, ébastante concorde com a concepção historiográfica defendida por filósofos como Foucault, mas também Bachelard e Canguilhem. Cf. Roberto Machado (1981), Jean-François Braunstein (2005), lan Hacking (2009), Gary Gutting (1999). 
dois modos de dizer e pensar a vida - ao que Foucault contrapõe para a modernidade com o termo "vida". O que podemos nos perguntar é: diante da biopolítica, das múltiplas estratégias políticas e governamentais que heuristicamente podem ser qualificadas como biopolíticas, o que o sintagma "vida" pode significar e designar? A ideia da recondução epistêmica do conceito de vida ao modelo zoológico é suficiente para definir o que é vida enquanto objeto primaz da(s) biopolítica(s)? Certamente não. Eis a minha hipótese: Ainda que reconheça a acepção ontológica daquela ideia de uma vida selvagem, então identificada por Tarizzo, o que mais me interessa, primeiramente, é esboçar uma interpretação que dê conta de explicitar essa adoção da animalidade por nós, os modernos, como elemento fulcral de enquadramento ${ }^{5}-$ no sentido então considerado por Butler (2016) - de nossa vida e de nosso viver.

Isto posto, é possível reintroduzir os dois grandes exemplos que Foucault fornece para pensar o tema da biopolítica, quais sejam, o da racialização do Estado e o da introdução do dispositivo da sexualidade. Destes dois grandes exemplos é possível se perguntar por suas condições de possibilidade, pois o pano de fundo arqueológico já está dado, isto é, da transformação da noção de vida e de seu estatuto, da história natural à biologia. Em outras palavras, o que sugiro é que, de um ponto de vista arqueológico, o tema do racismo e da sexualidade só se fizeram possíveis por essa transformação do solo arqueológico que possibilitou o surgimento da biologia; e neste sentido, é o mesmo solo que possibilitou algo tão complexo ao mesmo tempo que sutil, que se convencionou nominar "biopolítica".

É conhecida a estratégia argumentativa que Foucault monta para suas aulas de 1976, Il faut défendre la société. Para tratar do tema

5 E para mim, esse enquadramento se dá a partir de um processo de construção técnica da vida como objeto. 0 que tentarei mostrar em momento oportuno em outro texto. 
do racismo de Estado e suas implicações no curso da contemporaneidade ${ }^{6}$, ele mesmo observa no resumo do curso que estava em jogo nas suas investigações a possibilidade de utilizar a guerra como um operador analítico para compreender e analisar as relações de força, um elemento fundamental de inteligibilidade para as sociedades europeias, historicamente em formação, principalmente França, Inglaterra e Alemanha, e mesmo das relações sociais (FOUCAULT, 1997, p. 243; 1999, p. 324), ao mesmo tempo que era mister entender seu modo de funcionamento para possibilitar uma vitória sobre ela (FOUCAULT, 1997, p. 241; 1999, p. 322). A guerra não é apenas tomada por Foucault como um expediente hermenêutico, mas como a condição mesma de nossa existência e motor primevo do Estado e da sociedade:

A lei não é pacificação, pois sob a lei, a guerra continua a fazer estragos no interior de todos os mecanismos de poder, mesmo os mais regulares. A guerra é o motor das instituições e da ordem: a paz, na menor de suas engrenagens, faz surdamente a guerra. Em outras palavras, cumpre decifrar a guerra sob a paz: a guerra é a cifra mesma da paz. Portanto, estamos em guerra uns contra os outros; uma frente de batalha perpassa a sociedade inteira, contínua e permanentemente, e é essa frente de batalha que coloca cada um de nós num campo ou no outro. Não há sujeito neutro. Somos forçosamente adversários de alguém (FOUCAULT, 1997, p. 43s; 1999, p. 59).

É neste contexto que é preciso entender como se dão as estratégias da história das guerras das raças e como, pouco a pouco no curso da própria história, vai se introduzindo o tema do racismo e do racismo de Estado. O que passo a considerar agora, ainda que de modo sumário. Em que consiste a guerra das raças?

É a ideia segundo a qual a sociedade é, de um extremo a outro, percorrida por esse enfrentamento das raças, que encontramos formulado já no século XVII e como que a matriz de todas as formas sob as quais, em

6 Nunca é demais lembrar que o curso é dado ainda no auge da Guerra fria, inclusive com a ameaça constante do risco de se aquecer a guerra em dimensões nucleares. 
seguida, investigaremos a fisionomia e os mecanismos da guerra social (FOUCAULT, 1997, p. 51; 1999, p. 71).

Foucault observa que, desde o final do século XVIII até o fim do XIX, se vê surgir duas variantes dessa história da guerra das raças: uma de matriz biológica, que começa ainda antes de Darwin, e outra sócio-econômica em torno da introdução da tese da luta de classes, sendo que Foucault deixa claro que pretende se concentrar na primeira. Dessa forma, vê-se a substituição do modelo histórico da guerra pelo "tema biológico, pós-evolucionista, da luta pela vida. Não mais batalha no sentido guerreiro, mas luta no sentido biológico" (FOUCAULT, 1997, p. 70; 1999, p. 94); a substituição do tema utilizado por historiadores da luta, da guerra entre raças (propositalmente no plural) para o tema da pureza da raça (no singular, apostando num monismo biológico e também social). É o surgimento do racismo com sua carga biológica. Neste contesto, o Estado muda de configuração e de função: deixa de ser o instrumento de supremacia e domínio de uma raça sobre outra para se tornar o mecanismo próprio para proteção da raça: "A parecimento portanto, no fim do século XIX daquilo que poderíamos chamar de racismo de Estado: racismo biológico e centralizado" (FOUCAULT, 1997, p. 71; 1999, p. 96). Ora, o tema do racismo biológico só pode ser colocado deste modo porque o enquadramento da vida em perspectiva zoológica, animal, já está constituída, como se pode atestar pelo livro de 1961 de Foucault. A selvageria que passou a ser a marca da vida e, pois, da biologia, também ganha aqui seus contornos políticos.

Para os meus propósitos não cabe tecer considerações sobre boa parte daquele curso de 1976. É preciso ir até a última aula, exatamente a aula de 17 de março de 1976, na qual Foucault apresenta, talvez de modo mais contundente e dramático e que consiste, como funciona a biopolítica. Ela se inicia com Foucault mostrando o nascimento do racismo de Estado. Nascimento esse que é razoavelmente bem datado desde o fim do século XVIII e início do XIX. Foucault diz assim:

Parece-me que um dos fenômenos fundamentais do século XIX foi, é o que se poderia denominar a assunção da vida pelo poder: se vocês 
preferirem, uma tomada de poder sobre o homem enquanto ser vivo, uma espécie de estatização do biológico ou, pelo menos, uma certa inclinação que conduz ao que se poderia chamar de estatização do biológico (FOUCAULT, 1997, p. 213; 1999, p. 285s).

É curioso que para seguir sua análise ele retoma uma estratégia, de certo modo um tanto corriqueira de sua parte, pelo menos desde 1973, com seu curso Le pouvoir psychiatrique (FOUCAULT, 2003, p. 22-31; 41-63; 2006, p. 26-37; 49-77), quando ele toma a soberania como uma espécie de pano de fundo para uma contraposição histórica (a disciplina e a biopolítica são datadas em épocas distintas da soberania, a partir de um certo ocaso desta) e do tipo de um hibridismo onto-estratégico. Isto é, como se Foucault definisse o modo de ser político da disciplina e da biopolítica, mostrando como elas se diferem da soberania no que tange seus objetos e escopos, seus métodos e estratégias, e seus modos de funcionamento e tecnologias. Também é curioso que Foucault precisa demarcar a distância que separa a disciplina da biopolítica:

Ao que essa nova técnica de poder não disciplinar se aplica é - diferentemente da disciplina, que se dirige ao corpo - a vida dos homens, ou ainda, se vocês preferirem, ela se dirige não ao homem-corpo, mas ao homem vivo, ao homem ser vivo; no limite, se vocês quiserem, ao homem-espécie. [...] Depois da anátomo-política do corpo humano, instaurada no decorrer do século XVIII, vemos aparecer, no fim do mesmo século, algo que já não é uma anátomo-política do corpo humano, mas que eu chamaria de uma "biopolítica" da espécie humana (FOUCAULT, 1997 , p. 216; 1999, p. 289).

Outro elemento digno de nota é que as estratégias que Foucault se vale em Il faut défendre la société para, na sua última aula, colocar o tema da biopolítica, passam primeiro por uma demarcação entre história da guerra das raças e o racismo de Estado; depois pela contraposição entre soberania, disciplina e biopolítica, e só nessa contraposição que ele distingue, como que pela identificação dos objetos que lhes são próprios, biopolítica da disciplina. Exceto por algumas afirmações em algumas aulas, Foucault pouco diz sobre a vida. Suas considerações são mais da ordem da política, talvez em coerência com sua proposta desde 
o início de se perguntar sobre a possibilidade de pensar esse conjunto de fenômenos, estes que considera à luz do tema da guerra. O que ele faz a seguir é demarcar os domínios de atuação e um conjunto de fenômenos históricos próprios à biopolítica: Inicialmente, a partir da segunda metade do século XVIII dos processos de natalidade, mortalidade e longevidade, a partir do qual se assiste a utilização pela primeira vez de medições estatísticas e demográficas; a seguir se vê introduzir o problema da morbidade e das doenças e das endemias que acometem uma população - o que acaba por exigir uma medicina cuja função maior é o da higiene pública e medicalização da população. Outro domínio que parece se fazer presente surge a partir da problemática da velhice e da incapacitação ao trabalho, seja por enfermidade ou acidente, de tal modo que se introduz estrategicamente a possibilidade de pensar em instituições assistenciais ou mecanismos de seguridade, individual e coletiva; e por fim, último domínio enumerado por Foucault (mas que ele deixa claro que sua lista não é exaustiva e completa), a da relação entre população e seu meio ambiente como meio de existência, dos espaços insalubres como os pântanos, mas principalmente um meio não natural, criado pela própria população, mas que lhe é fundamental: a cidade. Na sua argumentação, realça qual o objeto-mor da biopolítica: a população.

Não é exatamente com a sociedade que se lida nessa nova tecnologia de poder (ou, enfim, com o corpo social tal como o definem os juristas); não é tampouco com o indivíduo-corpo. É um novo corpo: corpo múltiplo, corpo com inúmeras cabeças, se não infinito pelo menos necessariamente numerável. É a noção de "população". A biopolítica lida com a população, e a população como problema político, como problema a um só tempo científico e político, como problema biológico e como problema de poder, acho que aparece nesse momento (FOUCAULT, 1997, p. 218s; 1999, p. 293s).

Um elemento já nos chama a atenção aqui: a da aparente coincidência histórica entre os primeiros balbucios e formulações que implicaram no surgimento da biologia - considerados por ele em Les mots et les choses - e a emergência histórica dessa nova modalidade 
tecnológica de poder que é a biopolítica. Mas curiosamente ou não, Foucault não parece demonstrar grande interesse na coincidência, exceto para demarcar a distância que há entre biopolítica e disciplina. De qualquer modo, acredito que isto não nos autoriza a pensar num descaso da parte do filósofo sobre o estatuto constituído da vida em chave política; ou dito de outro modo: é necessário se perguntar pela biologização da vida para também entender, seja a emergência histórica da biopolítica, sejam seus objetos e modos de funcionamento estratégico, notadamente expressa naquela máxima: "fazer viver e deixar morrer" (FOUCAULT, 1997, p. 220; 1999, p. 294).

Fazer viver. É nessa aparentemente ingênua formulação que a biopolítica se coloca como historicamente possível. Ela alude não ao respeito ao estado natural das coisas. Não se trata jamais de estar de acordo com a natureza, com a defesa de sua inviolabilidade ou sacralidade, não se trata disso. Quando já em Les mots et les choses, Foucault afirma a condição selvagem da vida, o que ele quer dizer é sobre o reconhecimento da vida num processo constitutivo que tem na morte, ao mesmo tempo seu ápice e seu ocaso, como que duas forças contrastantes e opositivas, e por outro lado também reconhece a inerência quase trivial ao mesmo tempo que fulcral entre vida e morte. A vida, como uma força, é um constante mover-se em fuga e em resistência à morte. Contudo, é nessa dialética entre potências que se institui a condição distintiva do orgânico diante do inorgânico; do vivo diante do inerte. A morte é, paradoxalmente, seu limite: é o que há de mais privado à vida e o marco maior do ponto, do momento em que a vida se esvai de si mesma. De um ponto de vista da gestão e da administração política dos indivíduos e da população, não é a morte que conta, mas a "gestão calculista da vida" (FOUCAULT, 1976, p. 184; 1988, p. 131), donde a questão do limite político que a morte impõe (Cf. NALLI, 2012; 2014).

O que não deixa de nos colocar uma dificuldade. Quando em $L a$ volonté de savoir Foucault busca demarcar o que chamou de scientia sexualis, dessas ciências que no Ocidente moderno, principalmente depois do século XVIII, buscaram apreender a sexualidade, geralmente desde uma perspectiva majoritariamente médica, ele mesmo reconhece a defasagem epistemológica reinante entre os conhecimentos biológicos e 
os médicos, ou melhor, entre o que chamou de fisiologia da reprodução e a medicina da sexualidade. Ele reconhece a essa medicina uma indiscrição reinante e insistente, "mais servil ante às potências da ordem do que dócil às exigências da verdade" (FOUCAULT, 1976, p. 72; 1988, p. 54). E ele continua de modo bem mais contundente:

Quando se compara tais discursos sobre a sexualidade humana com o nível, na mesma época, da fisiologia da reprodução animal ou vegetal, a defasagem é surpreendente. Seu fraco teor, e nem mesmo falo de cientificidade, mas de racionalidade elementar, coloca-os à parte na história dos conhecimentos. Eles formam uma zona estranhamente confusa. $\mathrm{O}$ sexo, ao longo de todo o século XIX, parece inscrever=se em dois registros de saber bem distintos: uma biologia da reprodução desenvolvida continuamente segundo uma normatividade científica geral, e uma medicina do sexo obediente a regras de origens inteiramente diversas. Entre uma e outra nenhum intercâmbio real, nenhuma estruturação, a primeira desempenhou apenas, em relação à outra, o papel de uma garantia longínqua e, ainda assim, bem fictícia: de uma caução global sob cujo disfarce os obstáculos morais, as opções econômicas ou políticas, os medos tradicionais podiam-se reescrever num vocabulário de consonância científica (FOUCAULT, 1976, p. 73; 1988, p. 54s).

Ora, tal afirmação choca não apenas com nosso argumento geral. Choca também com as afirmações de Foucault, no mesmo livro, em seu último capítulo, principalmente quando, para demarcar a diferença entre a disciplina e a biopolítica, assim como já o havia feito antes na aula de 17 de março de 1976, no curso Il faut défendre la société. No capítulo, ele afirma categoricamente que a biopolítica

centrou-se no corpo-espécie, no corpo transpassado pela mecânica do ser vivo e como suporte dor processos biológicos: a proliferação, os nascimentos e a mortalidade, o nível de saúde, a duração da vida, a longevidade, com todas as condições que podem fazê-los variar; tais processos são assumidos mediante toda uma série de intervenções e controles reguladores: uma biopolítica da população. [...] do poder sobre a vida (FOUCAULT, 1976, p. 183; 1988, p. 131; destaque do autor). 
Assim, como entender aquela afirmação? Como contradição de Foucault? Como invalidação de meu argumento? Ou algo mais sutil, mas não menos importante? Vejamos:

A primeira citação afirma a não coincidência entre fisiologia da reprodução e medicina da sexualidade, que a diferença não é apenas epistemológica, mas que seus motivadores são totalmente distintos: a primeira de teor racional-científico; a segunda, de teor moral. Mais: que os aparentes pontos de contato são meramente fictícios. Mas isto quer dizer falsos? Creio que não. Apenas se trata de pontos estratégicos cuja finalidade maior é a da justificação cientificista a um conjunto de práticas, elas mesmas, de natureza e escopo diversos do das ciências: o recurso à biologia, especificamente à fisiologia da reprodução, parece legitimar, quase que como uma aparelhagem ideológica, aquelas práticas médicas devotadas à sexualidade. A segunda citação, no entanto, sugere um enquadramento diverso. Não se trata de justificação ideológica. Trata-se, sim, da constituição de todo uma rede de empiricidade toda nova, permeada, atravessada a um só tempo pelos conhecimentos advindos da biologia e graus diversos, e de um novo modo de operar politicamente sobre a vida. Se na primeira, é o tema da sexualidade que funciona como denominador e catalizador, sem necessariamente se articular àquele biológico, da reprodução, agora não se trata sequer de articulação entre dois fenômenos distintos, e sim de um mesmo fenômeno, ou do mesmo nome considerado para lidar com o mesmo conjunto de fenômenos. Tomemos um exemplo: os problemas próprios à natalidade não se confundem com o da mortalidade, exceto por indicarem os limites extremos da vida; cada um deles tem seus problemas específicos e abordagens, tanto científicas quanto políticas distintas; mas ambos remetem a mesma ideia geral como problemática, aquela da vida.

Então como entender a primeira citação? A minha hipótese é que, apesar das diferenças demarcadas de modo tão incisivo por Foucault, não invalida o fato de que a intrusão da medicina da sexualidade só pôde se dar e de modo ideologicamente justificado, tendo como pano de fundo a emergência biológica da vida, pela fisiologia da reprodução. Em linhas mais gerais, a emergência histórica da biologia, 
da biologização da vida, da adoção do animal para pensar (biologicamente) a vida, funciona como enquadramento ontológico, semântico e epistemológico - ontológico porque define um campo de empiricidades; semântico, pois introduz novas regras para nominar os espécimes e suas famílias, assim como estabelecer relações de homologia; epistemológico porque estabelece outros critérios de cientificidade permitindo novos saberes a partir de novos rearranjos das informações e dados outrora coletados - , permitindo assim que estratégias de saber-poder menos rigorosas de um ponto de vista epistemológico se tornem factíveis. Admitindo que como prática a medicina da sexualidade não é apenas discursiva, mas de fato pragmática intentando sobre as subjetividades das pessoas a partir da determinação objetiva de sua sexualidade, isto é, em sua condição de dispositivo da sexualidade, que tem no sexo, a "encruzilhada do corpo e da população": "De um modo geral, na junção entre o 'corpo' e a 'população', o sexo tornou-se o alvo central de um poder que se organiza em torno da gestão da vida, mais do que da ameaça da morte" (FOUCAULT, 1976, p. 193; 1988, p. 138; cf. NALLI, 2012; 2014).

Portanto, a questão da emergência desses dispositivos sobre o sexo, que têm talvez na medicina e na psiquiatria suas formulações mais evidentes, não é de qualquer modo uma contradição, apenas uma implementação estratégica, ainda que implique na perda de algum rigor quanto à cientificidade exigida. Por um lado, é um exemplo situado num quadro ampliado de uma problemática ao mesmo tempo da ordem do saber e da política: a vida - pela questão do sexo - como fenômeno a um só tempo científico e político. Por outro, a questão do sexo, nessa estruturação biopolítica que articula tanto o corpo (e como não dizer, dadas as críticas dirigidas por Foucault à psicanálise, também à psiquê) individual quanto a população, funciona como um dispositivo exemplar de toda análise sobre biopolítica à medida que a contempla em sua totalidade como que em duas vias distintas, porém complementares, uma individual e especificante, a outra global e sinótica ao considerar a população.

E por que isto é possível? Pelo simples fato de que a planta não tem sexo, apenas sistema reprodutor. Nela, tudo se explica e todas as 
suas partes se integram e concatenam pela reprodução, num esquematismo taxinômico, ainda que já se possa lhes atribuir alguma função. No animal, e em especial no animal humano, o que há é um sistema reprodutor e ademais, e até mesmo a despeito do sistema, um sexo. Um sexo que atravessa não apenas a genitália ou as partes componentes de seu sistema reprodutor; trata-se de um sexo que atravessa todo o corpo individual atribuindo-o em sua totalidade e a cada parte outras funções que não necessariamente a reprodução: a genitália pode servir tanto a uma função reprodutiva quanto a uma atividade sexual, sem necessariamente visar a reprodução (Cf. FOUCAULT, 1976, p. 201; 1988, p. 143). Isto explica a importância das figuras limites ao dispositivo da sexualidade: a histérica, a criança que se masturba, ao homossexual. Mas é também pelo sexo, pela sexualização do animal humano, que se atinge também sua condição de espécie, coletivamente, em sua condição de população. Portanto, o dizer sobre o sexo, dizer sobre nosso sexo e geri-lo, só é possível à medida que se lhe considera de modo fulcral à luz de nossa animalidade.

Neste contexto, a biopolítica só é possível a partir do reconhecimento de nossa animalidade, mas não como ser vivente, pura e simplesmente, como o era para Aristóteles. É preciso entendê-la, a vida, como sendo o caracterizador mesmo de nossa animalidade: a animalidade se esvai, se perde, assim como toda a condição de organismo, quando se morre, ainda que seja possível todo um inventário analítico do cadáver e mesmo uma história da fisiologia da morte. Mas é preciso sempre ter presente que a vida se explica em termos da animalidade; por isto, inclusive é que é possível uma fisiologia da morte relatada como se fosse uma história. Em suma, a inversão não é apenas entre os termos vida e política, mas da própria noção de vida, de tal modo que é a (nossa) vida que está em questão biopolítica, como jamais fora e como jamais poderia ter sido para Aristóteles e as gerações que se seguiram até o alvorecer da Modernidade.

Como se contrapor a tudo isso? Primeiramente não visando um retorno idílico a um passado outro que não vivemos e que jamais poderemos viver. Pensando sobre o dispositivo da sexualidade, Foucault dá uma espécie de pista possível, ainda que adstrita ao contexto do 
embate ao dispositivo da sexualidade: "contra o dispositivo da sexualidade, o ponto de apoio do contra-ataque não deve ser o sexo-desejo, mas os corpos e os prazeres" (FOUCAULT, 1976, p. 208; 1988, p. 147). Sabemos o que ele diz sobre isso, principalmente quando contrapõe a ars erotica à scientia sexualis (que é o dispositivo da sexualidade considerada pela via discursiva das ciências). Ela parece nos remeter ao passado greco-romano ou a algumas práticas orientais. Será este o caminho? Parece ser um caminho bastante forte a se considerar, principalmente se considerarmos os cursos após a publicação de Volonté de savoir bem como seus derradeiros livros. Mas talvez isto seja superficial, se não nos perguntarmos pelas razões estratégicas e mesmo metodológicas de Foucault para seu retorno aos gregos e romanos (e agora também sabemos aos primeiros séculos da Cristandade). Particularmente, acredito - e tomo isto como uma afirmação "cega", como uma crença, desprovida de qualquer justificação racional desenvolvida, exceto a razão de toda análise efetuada aqui - que o caminho é um pouco diverso: é preciso admitir a ironia de tudo isso; assim como Foucault parecia admitir que a liberação, alguma ao menos, poderia advir de acreditarmos, isto é, de levarmos a serio o dispositivo da sexualidade, acredito que, por analogia, devemos também levar a sério a condição presente na atualidade de nossa vida e - quem sabe? - buscar novos modos de lidar com nossa animalidade.

\section{Referências}

AGAMBEN, G. Homo sacer, I: Le pouvoir souverain et la vie nue. Paris: Seuil, 1997. BRAUNSTEIN, J-F. Bachelard, Canguilhem, Foucault: le « style français » en épistémologie. In: WAGNER, P. (dir.). Les philosophes et la science. Paris: Gallimard, 2005. p. 920-963.

BUTLER, J. Quadros de guerra: Quando a vida é passível de luto? Trad. de Sérgio T. de N. Lamarão e Arnaldo M. da Cunha. Rio de Janeiro: Civilização Brasileira, 2016. 
NALLI, M.

CASTRO, E. El vocabulário de Michel Foucault. Bernal: Universidad de Quilmes, 2004.

CHAUÍ, M. Da realidade sem mistérios ao mistério do mundo: Espinosa, Voltaire, Meleau-Ponty. São Paulo: Brasiliense, 1983.

FOUCAULT, M. "Prisons et asiles dans le mécanisme du pouvoir." In: Dits et écrits. Paris: Gallimard, 1994. p. 521-525. (Tome II).

FOUCAULT, M. As palavras e as coisas. Trad. De Salma Tannus Muchail. São Paulo: Martins Fontes, 1992.

FOUCAULT, M. Em defesa da sociedade. Trad. de Maria Ermatina Galvão. São Paulo: Martins Fontes, 1999.

FOUCAULT, M. Histoire de la sexualité, I: La volonté de savoir. Paris: Gallimard, 1976.

FOUCAULT, M. História da sexualidade, I: A vontade de saber. Trad. de Maria T. da Costa Albuquerque e J. A. Guilhon Albuquerque. Rio de Janeiro: Graal, 1988.

FOUCAULT, M. Il faut défendre la société. Paris: Gallimard; Seuil, 1997.

GUTTING, G. Michel Foucault's archaeology of scientific reason. New York: Cambridge University Press, 1999.

HACKING, I. Ontologia histórica. Trad. de Leila Mendes. São Leopoldo: EdUNISINOS, 2009.

JACOB, F. A lógica da vida. Lisboa: Publicações Dom Quixote, 1985.

MACHADO, R. Ciência e saber: A trajetória da arqueologia de Michel Foucault. Rio de Janeiro: Graal, 1981.

MERLEAU-PONTY, M. O visível e o invisível. Trad. de José Arthur Gianotti e Armando Mora d'Oliveira. São Paulo: Perspectiva, 1971.

NALLI, M. Foucault e a fenomenologia. São Paulo: Loyola, 2006. 
NALLI, M. "A imanência normativa da vida (e da morte) na análise foucaultiana da biopolítica: uma resposta a Roberto Esposito". O Que nos Faz Pensar (PUCRJ), v. 31, p. 149-174, 2012.

NALLI, M. "The normative immanence of life and death in Foucauldian analysis of biopolitics". Materiali Foucaultiani, v. III, p. 197-218, 2014.

TARIZZO, D. La vita, un'invenzione recente. Roma: Laterza, 2010.

Recebido: 18/01/2019

Received: 01/18/2019

Aprovado: 07/04/2019

Approved: 07/04/2019 